\title{
Trauma, Resilience and the Power of Human Connection: Reflections from the Field of Cambodia
}

\author{
Zoe Wyatt ${ }^{1,2, *}$, Mike Nowlin ${ }^{3, *}$ \\ ${ }^{1}$ Deakin University, Melbourne, Australia \\ ${ }^{2}$ The Cabin Group, Chiang Mai, Thailand \\ ${ }^{3}$ Hagar USA, Charlotte, North Carolina, USA
}

Email address:

zwyat@deakin.edu.au (Z. Wyatt), mike.nowlin@hagarinternational.org (M. Nowlin)

${ }^{*}$ Corresponding author

\section{To cite this article:}

Zoe Wyatt, Mike Nowlin. Trauma, Resilience and the Power of Human Connection: Reflections from the Field of Cambodia. American Journal of Applied Psychology. Vol. 8, No. 2, 2019, pp. 50-56. doi: 10.11648/j.ajap.20190802.14

Received: March 18, 2019; Accepted: June 11, 2019; Published: June 27, 2019

\begin{abstract}
Political and economic instability, poverty, war and terrorism, are just some of the harsh realities facing many young people globally. Various theoretical frameworks that conceptualize resilience exist in Western countries, yet there is limited research that looks specifically at resilience for children and young people in developing nations who have experienced significant trauma. Earlier research conducted with staff at Hagar International Cambodia (hereafter Hagar) indicated that for a child, recovery from trauma was contingent on their relationships and their ability to establish trust and connection to others. Hagar is a global human rights organisation, providing wraparound support services for women and children who have survived the most extreme cases of human rights abuse. There is much to be gained from the insight and lived experiences of those who have risen from complex trauma situations, such as the young people from Hagar. As such, research is currently being conducted which examines the resiliency factors that have contributed to these young people's overall wellbeing. This article will explore the intersection between relationships, trust and power of human connection for trauma survivors in Cambodia, bringing together current research with reflections from the field of Cambodia.
\end{abstract}

Keywords: Resilience, Cambodia, Childhood Trauma, Recovery, Connection, Relationships, Trust

\section{Introduction: The Impact of Trauma}

This research article focuses on the story of Hagar children's recovery from trauma and the underpinning factors that enabled them to 'bounce back' from severe adversity and complex trauma during critical developmental stages of their lives [1, 2]. Renowned neuroscientist and child psychiatrist Bruce Perry, defines trauma as "an experience or pattern of experiences, which impairs the proper functioning of the person's stress response system, making it more reactive or sensitive" [3]. Neuroscience aids in informing our understanding of what continued activation of the stress response does to the brain in early childhood, anticipatory anxiety and PTSD. Genes provide the basic blueprint and early childhood experiences enhance the blueprint by creating a reality for the child [4]. The younger the child when trauma occurs, the more likely a child is to disassociate as they cannot fight or flee. Whilst fear is frequently the reason that the brain shuts down and disassociates, hunger, thirst and exhaustion can have a comparable result [5]. For marginalized individuals, the unpredictably of living in poverty will create a much higher baseline level of distress. However, it is also important to note, that not every distressing event results in traumatic stress and brain changes for a child, with the short and long-term impact of events such as violence and abuse being influenced by several factors including:

a. The age of the child and developmental stage

b. The child's past experience with trauma

c. The child's perception of the danger and relationship with the perpetrator

d. What occurs in the aftermath of the trauma

e. The availability of trusted adults who can provide protection

f. Child Trauma Academy, 2018

In the case of chronic complex trauma (where a child 
experiences ongoing or multiple traumatic events) trauma can have a detrimental effect on the developing brain [3-5]. Clinical studies on brain development spanning almost two decades have indicated that children who experience prolonged abuse and/or neglect, will often experience developmental delays across a broad spectrum, affecting individuals well into adulthood $[6-8,4]$ ).

The longitudinal study 'Adverse Childhood Experience' (ACE) Study of 17,337 Kaiser Permanente (American HMO) members, which commenced in 1995 and continues today, demonstrates a strong correlation between childhood maltreatment and a host of other psychological and medical conditions, including depression, anxiety and addiction [7, 9-11]. The ACE study took eight adverse childhood experiences including domestic violence, abuse and household dysfunction and used an AEC score, which has a 'dose response' between cumulative childhood stress and adverse experiences and the link to comorbidity issues in later life [10]. The researchers' conclusions were that the accumulative exposure of adverse life events on the developing brain and stress response would result in multiple effects on brain function [10]. This type of trauma and changes to brain function, produces serious self-regulation deficiencies, often classified as 'affect dysregulation' which is inclusive of both hyper-arousal (fight/flight stress response) and disassociation (mentally going to a different place) [12, 13]. The findings of the ACE Study formed the basis for further research into the enduring effects of abuse and related adverse experiences in childhood, which there have now been hundreds of studies of different populations using this framework, providing further examples of the neurobiological effects' childhood trauma [7, 5].

\section{What Is Resilience}

A common definition of resiliency is the ability to 'bounce back' from adverse life events. Resilient people demonstrate the capacity to overcome traumatic experiences and recover after serious or life-threatening events [14]. Coping skills bolster resilience by allowing an individual to adjust to the demands and challenges in their presented lives [15]. According to von Eye, A. \& Schuster and Masten by understanding resilience and a young person's ability to adapt amidst destructive environments may enable us to determine appropriate interventions, thus circumventing the adverse outcomes of trauma [16, 17]. Resilience is a common, adaptive response, which conceptualizes coping strategies and competencies that are available to most people [17]. Researchers globally have investigated resilience in children and young people to learn about the processes that support positive adaption and inform practice and policy in the process [18]. Western literature in the resiliency space regards qualities that enhance resilience as; maintaining an internal locus of control, problem solving skills, self-regulation capabilities, family and community support, possessing a sense of mission, adaptive coping and realistic evaluation of the external environment $[19,15]$. Yet community-based resiliency research emerging from Cambodia and other developing nations points more towards a sense of meaning in life, hope, faith, optimism and motivation [20]. These key attributes in both bodies of literature intersect with wider protective factors of secure attachment, extended family, relationships with others and community attributes [21-23].

\subsection{Studying Cambodian Resilience}

Research with Cambodian trauma survivors tends to focus on the 'non-resilient' group and the high-prevalence of PTSD in the population. With a preference to studying individuals with psychiatric disorders and difficulties associated with complex trauma, of which there have been several well-known trauma studies [24-26]. A large percentage of Cambodians have been diagnosed with PTSD using Western diagnostic frameworks, which has been critiqued by researchers in the field as not being culturally applicable [27-30]. Critics found that the questioning technique utilized in many studies were not culturally sensitive and did not take into consideration the ways the Khmer experience, understand and respond to stress. Chhim a prominent Khmer psychiatrist, argues the validity of a PTSD diagnosis for Cambodians could "sufficiently capture the symptoms of distress as they are experienced by many KR survivors" [30]. Levine further suggests that the cultural idiom of distress he refers to as Baksbat which means broken courage, should be acknowledged by mental health professionals working with Cambodians [27]. Arguing that in doing so, it could aid in the development of policy to "provide appropriate support for traumatized Cambodians" [30]. Chhim further defines the symptoms of Baksbat as the "lack of trust in others, submissiveness, feeling fearful and being mute and deaf" which in Khmer is dam doeum kor [30].

How is it that individuals with experiences of human trafficking and early childhood sexual abuse recover and what can we do to promote health and positive development in the aftermath of such trauma? Research into the phenomena of Cambodian resilience has been sparse, but in comparative studies [22, 31, 23]. Traditional cultural and religious practices were factors that improved circumstances in their lives and strengthened their perceived identity and self-efficacy. What these studies found, was that the more active Cambodians were in their culture, religion and community, the more they seemed to thrive [31]. Research suggests that it is in an individual's culture, beliefs and community-based practices that enabled them to recover, but what is not clear is how or why this had had been achieved [22, 23]. The research further suggests that the physiological effects of trauma may be experienced and present in distinctly different ways to draw strength in the recovery process. By suspending some of our own preconceptions about what resilience and recovery from trauma 'looks like' and learning what reality is as it's experienced by Cambodian young people, we may gain understandings that can aid critical evaluation and enrich existing models. For many Cambodians, the sense of family and community-connectedness is very important and may be the most significant factor underpinning resilience 
for Cambodian trauma survivors.

\subsection{Models of Resilience}

Resilience research has been increasing dramatically over the years and has not been limited to the field of social sciences [17]. It has been argued that although theoretical research on resilience of family systems and individual resiliency emerged over 20-years ago, there is a new found sense of urgency for combining science and practice in the development of models that address these pressing concerns $[17,32]$. The clinical sciences paved the way for systematic study of resilience and the effects of adversity on mental health. Early models of individual resilience began to emerge with the work of Vygotsky (1978), Werner (1993), Anthony \& Cohler (1987) and Masten \& O'Doughert who's early influential work recognized the strikingly different variations in adaptive functioning of 'at risk' young people due to trauma, poverty, genetics and family history [34-37]. Individual case studies as well as positive adjustment in high-risk sample groups began to recognize important influences on coping abilities and individual's ability to adapt, that were not being captured in the body of existing research that focused wholly on risk and pathological progression $[37,17]$. The term 'stress resistance' was initially used to describe the phenomena, which was later known by scholars as 'resilience' [17]. The study of resilience broadly encapsulated the processes, capabilities and desirable adaption in the context of risk and adversity linked with dysfunction. As result of these early scholarly pioneers in the field, there are now multiple pathways of resilience theory within an integrated framework of theory and science [38].

Individual models of resilience have its origins in systems theory, which offers a framework for integrating resiliency science that incorporates models of stress and coping [17]. Masten \& Cicchetti (2016) ssummarize the themes underpinning a systems framework into principles with the following core ideas: multiple levels interact with each other to shape function and development; the capacity for adaption is dynamic and always changing; change is interconnected and the systems are interdependent [18]. These complex adaptive systems have profound implications for individuals as they are embedded in families and other systems such as peer groups, culture, community and schools [17]. For example, the resiliency of a Hagar child may be dependent on the resources and supports available and the many systems the child interacts with. Kinship family, caregivers, foster parents and key Hagar staff, are likely to have played a substantial role in this. As the child grows into a young adult, they are likely to have connected with other resources and relationships outside of Hagar's immediate support system.

For Hagar children, the connection to their school, community, the pagoda and to their family, are all influences on a child's life and resilience. Hagar has found that those who are able to maintain a sense of normalcy despite the trauma tend to adjust more readily. This is largely due to residential care no longer Hagar's preferred method, unlike many other NGOs in the region. To be able to honor a child's wishes (when safely able to accommodate them) to remain with family or kinship, or in a family-style alternative setting such as foster care is always preferable. Children coming into a residential center in the city after living in the country may be a huge shock, as the sights, sounds and smells may be different, counseling is new to them, within a new school environment. Everything has changed, so in essence they have been stripped of all sense of normalcy. Therefore, resiliency will take more time to establish as the child would need to feel safe, a sense of routine and trust with those around them.

\section{Relationships, Basic Trust and Developing Self-Regulatory Abilities in Childhood}

Resilience does not require rugged individualism, rather, it is relationships that determine the capacity to adapt and thrive in the face of adversity [11]. Much has been written on the role of healthy relational interactions and how it may buffer the impact of childhood trauma, focusing on the connection between a child and caregiver as both the potential source of a child's distress, but also the solution to the distress [12, 39-41], highlight this relationship in terms of trauma impact on the developing brain. Looking at early childhood social and emotional development by unpacking the organisation of the brain based on a template laid down by the primary caregivers. For example, attuned caregivers allow the brain to develop with a template of humans as safe and predictable, being a source of comfort, pleasure and sustenance. Alternatively, a caregiver who is neglectful, or chaotically preoccupied, will provide a template in which humans are unpredictable and a source of pain, loss, chaos and fear. Relationships in early childhood thus change the vulnerability-resilience balance for a young person, who develops an activated stress response and is less receptive to developing a relational competence to safeguard and heal following trauma [41]. So despite the widespread belief that strength of character and individual grit will triumph over adversity, research now demonstrates that it is in fact the relationship with at least one supportive adult that will provide opportunities for the child to develop effective coping skills [17]. Clinicians need to work diligently to establish rapport in a safe manner, and as quickly as possible thus likely engaging in activities that the child likes to do to help them relax, have fun, burn off stress. While this can be accomplished in an office setting, there are real benefits to community-based interventions [42].

At Hagar, there is an educational focus within communities in order to educate family members on the impact of trauma. When children can be placed with family members safely, then they have a relationship foundation to more readily build upon. If a parent encourages the child to meet with the therapist, the child would frequently be more receptive than if the child meets them in a strange environment such as residential care. When children can't stay home due to safety issues, it is critical all possible safe kinship options (such as extended family and neighbors) are explored. That way, Hagar 
children can have a natural, safe, adult connection from the beginning of their treatment and recovery from trauma.

The Secure Base Model

These "first relationships are the prism through which young children learn about the world, including the world of people and self" (Thompson, 2002 p. 10), and post trauma, these positive relationships can also be protective and reparative. An extensive body of research exists advocating social connectedness as the key protective factor against many forms of trauma $[12,39,40][5,4]$. Ludy-Dobson \& Perry argue that child welfare, mental health and judicial systems operate as if they are "unaware of these essential findings in development, attachment and trauma" [41]. Instead, they move children from home to home, school to school, therapist to therapist, exacerbating or even replicating the relational imbalance and trauma in the child's life. The availability of at least one supportive and stable relationship between a child and an important adult can help children to counterbalance significant adversity within the safety of that relationship and begin to build a sense self-efficiency.

The Secure Base Model draws from attachment theory and was developed by Schofield \& Beek from the Centre of Research on Children and Families in the United Kingdom [44]. This model is also used by the Australian Government Child Protection in foster care training and practice. The framework proposes five dimensions of caregiving which overlap to create a secure base, allowing for maximum developmental benefit for the child as represented below:

\section{The Secure Base Model}

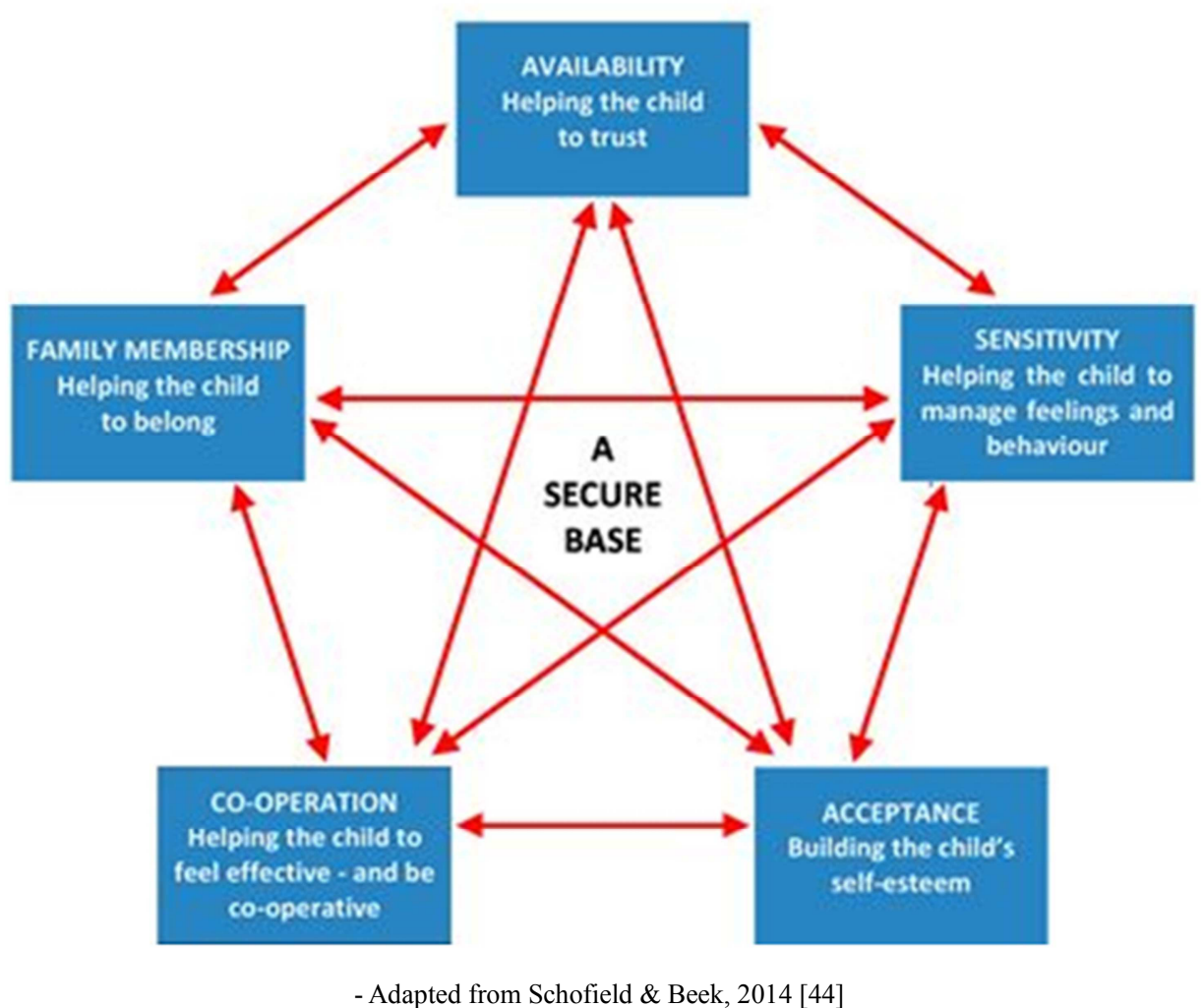

Figure 1. The Secure Base Model.

This secure base, or 'background of safety' must be present for basic trust to be established and secure attachments to formed during the lifespan. It is unclear whether basic trust can be reformed in a traumatised adult, when secure attachments were never formed in childhood [37]. This basic trust lays the foundation for social cohesion and relationships with significant others later in life. It is in this, where resilience thrives - in our connections to others. Culture is another important factor underpinning resilience, with studies demonstrating individuals with strongly aligned cultural values (also benefitting from social support) are shielded to a degree, by their traditional culture [37, 5]. However, the alternate option is that it has a detrimental effect on individual suffering and how it is experienced in Cambodia's collective history of traumatization and its "shared cultural universe" [45], p.583. Although there is no clear, universally agreed-upon explanation as to how culture, employment and social cohesion shape responses to healing, there have been many studies concluding the relationship between community, connection to others, sense of belonging can be found through these lifestyle factors $[37,45]$.

\section{Family, Social Cohesion, Work and Culture in Cambodia}

As highlighted earlier, modern neuropsychological research has shown that the ability to recover from trauma is often 
contingent on our ability to form trusting relationships with others, which is the baseline of social cohesion. Siegel found that an individual's ability to self-sooth negative internal dialogue may come from a memory of a parent who comforts or cheers up a child when in distress by offering emotional support [4]. Further studies suggest that the presence of a family had enhances psychological wellbeing and that healing from trauma occurs through the therapeutic activity taking place between a young person and their family and friends [46, 37]. Some studies that examined the resilience of Cambodian children after the war, many of whom were suffering from PTSD symptoms, including documented hyper-vigilance startle response and disassociation, found that their resilience came from the family unit $[47,48]$. With the study [48] concluding that "despite the horrific political violence under the KR Regime, I have never seen a group of children in all my years of work, who are more resilient and perceptive" (p.266).

Furthermore, Masten and Masten \& Ciccheti (2016) emphasize behavioral-psychosocial and neurobiological characteristics, arguing that all children need basic encouragement and opportunities throughout development in oder to succeed [17, 18]. Although acknowledging definitions of resilience may vary across cultures, resilience remains associated with secure attachment relationships [17]. A recent study that looked at resilience and healing among Cambodian survivors illustrated the multiple layers of collective adaptive factors that made up resilience, concluding that Cambodian people are highly family orientated and this was a defining factor [45]. These strong family bonds and sense of loyalty to the family is often witnessed by Cambodians living in an extended family, or a three-generation household [49]. The cultural tradition of filial piety or the belief that children should respect and take care of their parents is often followed [49]. The presence of a family can help as it provides a potential forum for the expression of feelings [46]. While social support structures and communities provided a further platform for connection and being able to talk to "someone who knows me" [37].

Culture and employment are primary sources of identity for most adults that correlate with a sense of belonging, meaning and purpose in an individual's life. Studies linking unemployment and poor mental health outcomes of traumatized populations have found that there is a significant relationship between work status and depression [22]. Beyond the family unit, research indicates that community context and community resilience are important for survivors of trauma $[50,14,51]$. It is well supported by the literature that much like employment for sense of purpose, culture within the community has a way of providing an identity for individuals in terms of norms and values by supplying a shared vision for the future $[37,23,45,17]$. The social and religious rituals tied to Khmer culture can play an important healing role. Examples of the interplay between work, cultural and social factors underpinning wellbeing are evident in the literature, with one such definition being the social conception of wellbeing itself. Developed by the Research Group on
Wellbeing in Developing Countries (WeD) arguing that that the notion of wellbeing is a social construct, dependent largely on culture and community values [52]. Building on this work, [53] defined social wellbeing as "A state of being with others and the natural environment that arises where human needs are met, where individuals and groups can act meaningfully to pursue their goals, and where they are satisfied with their way of life" [53]. In their definition, human wellbeing is made up of five components: basic material needs, health, security, good social relations, and freedom of choice and actions. A social conception of wellbeing nests the individualistic and basic needs aspects of wellbeing within the wider social and cultural needs required to live well $[54,55]$.

\section{In Conclusion: Practice Implications and Reflections from the Field of Hagar International}

Clinicians will often look towards the adults for responses during an intake assessment thinking that they will get the most reliable and pertinent information and in some instances there is some grain of truth in such an assumption. However, with a research-based understanding of the importance of identifying safe adults and other key relationships for child trauma survivors, clinicians must find meaningful ways to fully engage children in the assessment process in order to have the best treatment outcomes. Children are capable of sharing names of adults who are crucial resources to their personal stability and connectedness in their community. They can even share key characteristics of these adults so we can discover which attributes are most important to help the child feel safe, secure and nurtured. Children are also able to discuss which activities in their lives bring them joy, help them to connect to their community, and feel well-grounded. While we understand that every child trauma survivor is not able to be maintained in their own home due to safety reasons, this pertinent information should significantly influence the placement of a child in an alternative safe accommodation such as kinship or foster care.

A residential recovery model for children who have been victims of trafficking, abuse and exploitation has been used in numerous developing countries and Hagar had previously used such a model for over two decades. It is understandable that many organisation s, practitioners and funders would state this is the safest manner to complete aftercare services as you can "guarantee" 24/7 supervision and security. However, what Hagar has found is that a blanket use of residential recovery services for child survivors removes connections to family and community, both significant resources when seeking to build resiliency. This practice often requires children to leave everything familiar: home, school, community, friendships, activities, and safe adults. As Hagar stopped and asked children and adult survivors what they really wanted, their responses indicated that being in residential care was generally at the bottom of the list. Survivors wanted to receive services in their community, and as a result, Hagar began the 
shift to using an intensive community-based model of care to treat trauma for all but the most severe instances.

The transition has not been without its challenges, but Hagar has found that children are generally happier, more connected, more motivated, and have a safe environment for resiliency to flourish. So regardless of age, clinicians and those working to support survivors, need to ensure that self-determination is strongly considered along with safety needs when conducting assessments and making treatment or placement recommendations for a child. If we can help survivors feel empowered at the onset of their recovery, the more invested they will be in the process, which generally leads to more effective service delivery and better treatment outcomes.

"The more healthy relationships a child has, the more likely they will be to recover from trauma and thrive. Relationships are the agents of change and the most powerful therapy is human love" - Bruce D Perry (2006, p. 36)

\section{References}

[1] Wyatt, Z. Hoban, E. McFarlane, S. 2018, Trauma-Informed Education Practice in Cambodia, International Journal of Asian Social Science, vol. S, no. 2, pp. 62-76.

[2] Hagar International USA, 2016. Hagar's Story. Available at: https:/hagarinternational.org/usa/about/hagars-story/ [Accessed November 2018].

[3] Perry, B., 2006. Applying principles of neurodevelopment to clinical work with maltreated and traumatized children. In: N. Webb, ed. Working with traumatized youth in child welfare. New York: Guildford Press, pp. 27-52.

[4] Siegel, D., 2015. The Developing Mind: How relationships and the brain interact and shape who we are. The Guilford Press, New York.

[5] van der Kolt, B., 2015. The body keeps the score: Brain, mind, and body in the healing of trauma. New York: Viking.

[6] Teicher, M. et al., 2002. Developmental neurobiology of childhood stress and trauma. Psychiatr Clin North Am, 25 (2), pp. 397-426.

[7] Anda, R. et al., 2005. The enduring effects of abuse and related adverse experiences in childhood. A convergence of evidence from neurobiology and epidemiology. Eur Arch Psychiatry Clin Neurosci, 256 (3), pp. 174-86.

[8] De Bellis, M., Hooper, S., Woolley, D. \& Shenk, C., 2010. Demographic, maltreatment, and neurobiological correlates of PTSD symptoms in children and adolescents. Pediatr Psychol, 35 (5), pp. 570-7.

[9] Walker, E. et al., 1999. Adult health status of women with histories of childhood abuse and neglect. Am JMed, 107 (4), pp. 332-9.

[10] Scott, J. Varghese, D. \& McGrath, J., 2010, As the twig is bent, the tree inclines: adult mental health consequences of childhood adversity. Archives of General Psychiatry, 67 (2), pp. 111-112.

[11] Wylie, S. M., 2012. As the Twig is Bent: Understanding the health implications of early life trauma. http://www.westweb.com/sutker2012/wp-content/uploads/201 2/12/1107-as-the-twig-is-bent.pdf [Accessed November 2018].

[12] Downey, 2007. Calmer Classrooms: A Guide to Working with Traumatised Children. Child Safety Commissioner, Victorian Government. $\quad$ http://www.ccyp.vic.gov.au/childsafety commissioner/downloads/calmer_classrooms.pdf [Accessed June 2018].

[13] Zeigler, D, 2013, Optimum Learning Environments for Traumatized Children: How Abused Children Learn Best in School, Jasper Mountain, pp. 1-8, http://www.jaspermountain.org/optimum_1 [Accessed May 2018].

[14] Masten, A. \& Obradovic, J., 2008. Disaster Preparation and Recovery: Lessons from Research on Resilience in Human Development. Ecology and Society, 13 (1), p. 9.

[15] Heffron, K., 2013. Positive Psychology and the Body: The somatopsychic side to flourishing. s.1.: Open University Press.

[16] von Eye, A. \& Schuster, C., 2000. The odds of resilience. Child Development, 71 (3), pp. 563-566.

[17] Masten, A. S., 2018. Resilience Theory and Research on Children and Families: Past, Present, and Promise. Journal of Family Theory \& Review, 10 (1).

[18] Masten, A. S. \& Cicchetti, D., 2016. Resilience in Development: Progress and Transformation. In: D. Cichetti, ed. Developmental Psychopathology. s.1.: s.n.

[19] McAdam-Crisp, J. L., 2006. Factors That Can Enhance and Limit Resilience for Children of War. Childhood, 13 (4), pp. 459-477.

[20] Masten, A. S. \& Monn, A. R., 2015. Child and Family Reslience: A Call for Integrated Science, Practice, and Professional Training. Family Relations, 64 (1).

[21] Perry, B., 2009. Examining child maltreatment through a neurodevelopmental lens: Clinical applications of the neurosequential model of therapeutics. Journal of Loss and Trauma, 14 (4), pp. 240-255.

[22] Overland, G. \& Yenn, V., 2007. Generosity and Resilience; Transnational Activity among the Khmer of Norway. Urban Refugees, 24 (1), p. 129.

[23] Agger, I., 2015. Calming the mind: Healing after mass atrocity in Cambodia. Transcult Psychiatry, 52 (4), pp. 543-560.

[24] Mollica, R., 2006. Healing invisible wounds. New York: Harcourt, Inc.

[25] Van de Put, W. \& Eisenbruch, M., 2002. The Cambodian experience. In: J. de Jong, ed. Trauma, war, and violence. New York: Plenum, pp. 93-155.

[26] Marshall, M. Lewis, S. Lockwood, A. Drake, R. Jones, P. Croudace, T., 2005. Association between duration of untreated psychosis and outcome in cohorts of first-episode patients: a systematic review. Arch Gen Psychiatry, 62 (9), pp. 975-83.

[27] Levine, P., 2010. In an unspoken voice: How the body releases trauma and restores goodness. Berkeley, CA: North Atlantic Books.

[28] Hinton D. E. Nickerson A. Bryant R. A., 2011. Worry, worry attacks, and PTSD among Cambodian refugees: A path analysis investigation. Social Science and Medicine vol. 72 pp. 1817-1825. 
[29] Hinton D. E. Pich V. Hofmann S. G. Otto M. W., 2013. Mindfulness and acceptance techniques as applied to refugee and ethnic minority populations: Examples from culturally adapted CBT (CA-CBT), Cognitive and Behavioral Practice, vol. 20, pp. 33-46.

[30] Chhim, S., 2013. Baksbat (broken courage): a trauma-based cultural syndrome in Cambodia. Med Anthropol, 32 (2), pp. 160-73.

[31] Overland, G., 2013. Post Traumatic Survival: The Lessons of Cambodian Resilience. Cambridge: Cambrdige Scholars Publishing.

[32] Doty, J. L., Davis, L. \& Arditti, J. A., 2017. Cascading Resilience: Leverage Points in Promoting Parent and Child Well-Being. Journal of the Family Theory \& Review, 9 (1).

[33] Vygotsky, L., 1978. Mind in society: The Development of higher psychological processes. Cambridge, MA: Harvard University Press.

[34] Werner, E., 1993. Risk, resilience, and recovery: Perspectives from the Kauai Longitudinal Study. Development and Psychopathology, Volume 5, pp. 503-515.

[35] Anthony, E. \& Cohler, B., 1987. The invulnerable child. New York: Guildford Press.

[36] Masten, A. \& O'Dougherty-Wright, M., 1998. Cumulative Risk and Protection Models of Child Maltreatment. Journal fo Aggression, Maltreatment \& Trzauma, 2 (1), pp. 7-30.

[37] Overland, G., 2011. Promoting the resilience of post-conflict survivors: Findings from a study of resilient Cambodians, European Journal of Psycotraumatology, ISSN 2000-8198, 2011/106

[38] Wright, A. G. Krueger, R. F. Hobbs, M. J. Markon, K. E. Eaton, N. R. Slade, T., 2013. The Structure of Psychopathology: Toward an Expanded Quantiative Empirical Model. J Abnorm Psychol, 122 (1), pp. 281-294.

[39] Fecser, M., 2015. Classroom strategies for traumatized, oppositional students. Reclaiming Children and Youth, 24 (1), pp. 20-24.

[40] Brunzell, T, Stokes, H. \& Waters, L, 2015. Trauma-Informed Positive Education: Using Positive Psychology to Strengthen Vulnerable Students', Contemporary School Psychology, http://link.springer.com/article/10.1007\%2Fs 40688-015-0070-x [Accessed June 2018]

[41] Ludy-Dobson, C. \& Perry, B., 2010. The rol,e of health interaction in buffering the impact of childhood trauma. In: E. Gil, ed. Working with children to heal interpersonal trauma: The power of play. New York: Guildford Press, pp. 26-43.

[42] Child Welfare Committee, 2008, 'Child Welfare Trauma Training Toolkit: Comprehensive guide', National Child
Traumatic Stress Network, $2^{\text {nd }}$ edn, CA \& Durham, NC: National Centre for Child Traumatic Stress, http://www.nctsn.org/

[43] Thompson, N., 2002. Social Movements, Social Justice and Social Work. The British Journal of Social Work, 32 (6), pp. 711-722.

[44] Schofield, G. \& Beek, M., (2014). The Secure Base model: promoting attachment and resilience in foster care and adoption, London: BAAF.

[45] Greene, R., 2015. Resilience and Healing Among Cambodian Survivors of the Khmer Rouge Regime. J Evid Inf Soc Work, 12 (6), pp. 579-87.

[46] Lie, B. Sveaass, N. \& Eilertsen, D. E., 2006. Family, activity and stress reactions in exile, Community, work and family, 7 (3), pp. 327-350.

[47] Carlson, E. B. \& Rosser Hogan, R., 1993. Mental health status of Cambodia refugees ten years after leaving their homes. American Journal of Orthopsychiatry, 63 (2), pp. 223-231.

[48] Coles, R., 1986. The Political Life of Children. Boston: Houghton Mifflin.

[49] Chan, S. \& Kim, A. U., 2003. Not Just Victims: Conversations with Cambodian Community Leaders in the United States. Urbana and Chicago: University of Illinois Press.

[50] Betancourt, T. \& Khan, K., 2008. The mental health of children affected by armed conflict: protective processes and pathways to resilienc3. Int Rev Psychiatry, 20 (3), pp. 317-28.

[51] Norris, F. Stevens, S. P. Pfefferbaum, B. Wyche, K. F, \& Pfefferbaum, R. L. 2008. Community resilience as a metaphor, theory, set of capacities, and strategy for disaster readiness. $\mathrm{Am}$ J Community Psychol, 41 (1-2), pp. 127-50.

[52] Gough, I. \& McGregor, J., 2007. Wellbeing in developing countries: From Theory to Research. Cambridge: Cambridge University Press.

[53] Armitage, D. C. Brene, A. T. Charles, D. Johnson, \& Allison, E. $\mathrm{H}$. The Interplay of Well-being and Resilience in Applying a Social-Ecological Perspective. Ecology and Society, 17 (4), p. 15 .

[54] Deneulin, S. \& McGregor, J. A., 2010. The capability approach and the politics of a social conception of wellbeing. European Journal of SOcial Theory, 13 (4), pp. 501-519.

[55] Coulthard, S., Johnson, D. \& McGregor, J. A., 2011. Poverty, sustainability and wellbeing, A social wellbeing approach to the global fisheries crisis. Global Environmental Change, 21 (2), pp. 453-463. 